\title{
Functional role of RBM10 in lung adenocarcinoma proliferation
}

\author{
XIUNA SUN ${ }^{1}$, MENGQI JIA ${ }^{1}$, WEI SUN ${ }^{1}$, LU FENG $^{2}$, CHUNDONG GU $^{3}$ and TAIHUA WU ${ }^{1}$ \\ Departments of ${ }^{1}$ Respiratory Medicine, ${ }^{2}$ Pathology, and ${ }^{3}$ Thoracic Surgery, \\ The First Affiliated Hospital of Dalian Medical University, Dalian, Liaoning 116011, P.R. China
}

Received February 28, 2018; Accepted October 23, 2018

DOI: 10.3892/ijo.2018.4643

\begin{abstract}
Lung cancer is one of the most common causes of morbidity and mortality among malignant tumors worldwide. The poor prognosis of patients with lung adenocarcinomas is primarily due to its strong ability to invade and metastasize. Recent research has indicated that $R N A$-binding protein 10 ( $R B M 10)$ is mutated in lung adenocarcinoma, and is closely associated with tumor proliferation and apoptosis; however, the precise role of RBM10 in lung adenocarcinoma remains unclear. Our preliminary experiments (unpublished data) revealed that RBM10 expression was upregulated in lung adenocarcinoma cell lines and tissues. In this study, we first detected the protein expression level of RBM10 in lung adenocarcinoma cells and tissues, and we then examined the effects of RBM10 overexpression and downregulation (via small interfering RNA) on the proliferation and apoptosis of stable lung adenocarcinoma cells, along with its possible mechanisms of action. We also used clinical samples of lung adenocarcinomas to verify our results. We found that RBM10 protein was overexpressed in lung adenocarcinoma cells and tissues, and it reduced p53 expression (as detected by immunofluorescence assay and western blot analysis) in A549 cells and inhibited apoptosis (as shown by flow cytometric assay). RBM10 also promoted cell growth and proliferation in vitro and increased cell migration in a cell wound scratch assay. Furthermore, we found that RBM10 activated key proliferative signaling pathways [such as the epidermal growth factor receptor (EGFR), mitogen-activated protein kinase (MAPK) and phosphoinositide 3-kinase (PI3K)-AKT pathways] and inhibited apoptotic pathways. In addition, we demonstrated that a high expression of RBM10 protein in patient tissue samples
\end{abstract}

Correspondence to: Professor Taihua Wu, Department of Respiratory Medicine, The First Affiliated Hospital of Dalian Medical University, 222 Zhongshan Road, Dalian, Liaoning 116011, P.R. China E-mail: wutaihuadoc@126.com

Professor Chundong Gu, Department of Thoracic Surgery, The First Affiliated Hospital of Dalian Medical University, 222 Zhongshan Road, Dalian, Liaoning 116011, P.R. China

E-mail: chundong2003@163.com

Key words: lung adenocarcinoma, RNA-binding protein 10, proliferation, apoptosis was associated with a shorter overall survival time and a poor prognosis. On the whole, the findings of this study indicate that RBM10 may function as an oncogene in lung cancer, and may thus prove to be a novel therapeutic target for the prophylaxis and treatment of lung adenocarcinomas.

\section{Introduction}

Lung cancer is the most common malignant carcinoma worldwide (1). Due to its complex etiological mechanisms, rapid disease progression and lack of effective therapeutic drugs, it has become the main cause of cancer-associated mortality. Therefore, finding methods with which to effectively delay the progression of lung cancer, or treat the disease, is of great clinical concern.

Lung adenocarcinoma is the most common type of lung cancer $(2,3)$. The proliferation and metastasis of lung adenocarcinoma is key for disease progression (4). The excessive activation of multiple cell factors, oxidative stress factors and signaling pathways is known to contribute to tumor cell proliferation and metastasis $(5,6)$. However, the precise reason for the proliferation and metastasis of lung adenocarcinoma remains unclear.

Elevatedepidermalgrowthfactorreceptor(EGFR)-mediated proliferative signaling is an independent factor leading to tumor progression (6), although anti-EGFR therapies fail to exhibit satisfactory efficacy in some patients with lung cancer (7). In addition to EGFR mutations, recent studies have found that a mutation in the RNA-binding protein 10 (RBM10) gene is also an important event in tumor progression in certain types of cancer (2,8-12). RBM10 is involved in the tissue damage repair and various cell processes $(13,14)$. RBM10 mutations can result in the continuous proliferation and infiltration of tissues and cells $(14,15)$, and therefore accelerate disease progression. It was thus hypothesized that RBM10 protein overexpression may be essential, not only for causing tumor cell proliferation and metastasis, but also for the proliferation of stromal cells in the tumor microenvironment and epimatrix deposition.

Based on previous studies, we hypothesized that apoptosis would be inhibited and multiple proliferative signaling pathways would be excessively activated (likely due to inflammation or oxidative stress) in lung adenocarcinomas. However, whether RBM10 represents a common target for controlling the activity of such pathways, or for promoting apoptosis, is unclear.

In this study, we examined the effects of RBM10 overexpression and downregulation on lung tumor proliferation 
and apoptosis in vitro and in vivo. We also determined whether RBM10 expression is associated with the prognosis of lung cancer. This study provides important insight into the effects caused by RBM10 gene mutations in lung adenocarcinomas.

\section{Materials and methods}

Cells, cell culture and passage. Human lung adenocarcinoma cell lines (A549 and H1299) and human lung fibroblast cells (HLF), were purchased from the American Type Culture Collection (ATCC, Manassas, VA, USA) and maintained in the Central Laboratory of Dalian Medical University (Dalian, China). The H1299 and A549 cells were grown in RPMI-1640 medium, which contained $10 \%$ fetal bovine serum and the HLF cells were cultured in DMED/F12 medium. All the cells were maintained in a $37^{\circ} \mathrm{C}$ incubator under an atmosphere of $5 \% \mathrm{CO}_{2}$. The medium was changed every day and passaged when the cells grew to $80 \%$ confluence following trypsinization.

Lung tissue specimens. Lung tissue specimens were collected from patients with lung adenocarcinoma $(\mathrm{n}=6)$ and adjacent non-cancerous tissues (NCTs) $(n=6)$ were also collected for use in immunohistochemistry and western blot analysis (all samples were collected from April, 2015 to October, 2015). These patients were operated and diagnosed as having lung adenocarcinoma at the First Affiliated Hospital of Dalian Medical University. None of the patients had received chemotherapy or radiotherapy prior to surgery. The samples were stored at $-80^{\circ} \mathrm{C}$ until use in the experiments. Informed consent was obtained from all patients. This study was approved by the Human Research Ethics Committee of the First Affiliated Hospital of Dalian Medical University.

Lung adenocarcinoma tissue microarray. Survival data from a lung adenocarcinoma tissue microarray (90 lung adenocarcinoma tissues and $90 \mathrm{NCTs}$ ) were provided by Shanghai Outdo Biotech (Shanghai, China). None of the patients received chemotherapy or radiotherapy prior to surgery and had completed 5 years of follow-up.

Construction and transfection of high and low RBM10 expression cell strains. The pcDNA3.1RBM10 plasmid vector and RBM10 siRNA were constructed by ShangHai GenePharma Co. (Shanghai, China). The sequences of RBM10 siRNA were as follows: RBM10 siRNA-1, 5'-CCGAGAGAAGUGCUUCA AATT-3'; RBM10 siRNA-2, 5'-CCACACAGCACCAUGGAU UTT-3'; RBM10 siRNA-3, 5'-GGACAUGGCCUCCAA UGAATT-3'. The sequence of the negative control (mock) siRNA was as follows: 5'-UUCUCCGAACGUGUCACG UTT-3'. RBM10 shRNAs were purchased from Sigma-Aldrich (St. Louis, MO, USA). The sequences of RBM10 shRNA were as follows: RBM10 shRNA-D1, 5'-CCGGCAAGGGTTCTA AGAGGGACATCTCGAGATGTCCCTCTTAGAACCCTTG TTTTTG-3'; RBM10 shRNA-D2, 5'-CCGGCAAGACCAT CAATGTTGAGTTCTCGAGAACTCAACATTGATGGTCT TGTTTTTG-3'; RBM10 shRNA-D3, 5'-CCGGGACATGGAC TACCGTTCATATCTCGAGATATGAACGGTAGTCCATG TCTTTTTG-3'; RBM10 shRNA-D4, 5'-CCGGGCCCGCAG TCTCAACAAACAACTCGAGTTGTTTGTTGAGACTGCG GGCTTTTTG-3'.
The A549 and H1299 cells in the third generation logarithmic growth phase were selected. A total of $2 \times 10^{3}$ cells per well were inoculated in a sterile 24 -well culture plate for $12 \mathrm{~h}$. For the overexpression of RBM10, the cells were transfected with the pcDNA3.1RBM10 plasmid with liposome particles. To inhibit RBM10 expression, the cells were transfected with RBM10siRNA or RBM10 shRNA, using Lipofectamine 2000 (Invitrogen/Thermo Fisher Scientific, Waltham, MA, USA). A mock transfection was also performed using an empty vector. At $48 \mathrm{~h}$ following transfection, protein expression was examined by western blot analysis.

Western blot analysis. The cells were harvested following trypsinization and washed 3 times using PBS. A total of $1 \times 10^{7}$ cells were incubated in RIPA lysis buffer for $60 \mathrm{~min}$ at $4^{\circ} \mathrm{C}$. The cells were pipetted every $10 \mathrm{~min}$ during incubation and centrifuged at $20,800 \mathrm{x}$ g for $2 \mathrm{~min}$ at $4^{\circ} \mathrm{C}$. The supernatant was harvested and the protein concentration was measured using the BCA kit (GenePharma Co.) according to manufacturer's instructions, prior to storage at $-20^{\circ} \mathrm{C}$.

A 5\% stacking gel and $12.5 \%$ acrylamide separating gel were used in the procedure. A $10 \mu$ l sample was then mixed with $5 \mathrm{X}$ loading buffer at a 4:1 ratio. Following denaturation by boiling, the samples were loaded and resolved via $10 \%$ SDS-PAGE followed by transfer onto a nitrocellulose membrane. The membrane was blocked in 5\% non-fat milk in PBS for $1 \mathrm{~h}$ at room temperature and incubated with the primary antibody overnight at $4{ }^{\circ} \mathrm{C}$, followed by the addition of the secondary antibody for $2 \mathrm{~h}$ at room temperature. The membrane was washed for $5 \mathrm{~min}$ in TBST 3 times, and then visualized using the cECL kit (Zhong Shan-Golden Bridge Biological Technology, Beijing, China). Quantification of the bands was carried out using the Molecular Imager Chemi Doc XRS + Imaging System (Bio-Rad Laboratories, Hercules, CA, USA).Western blot analysis was repeated 3 times. The antibodies used were as follows: Rabbit anti-RBM10 (ab72423, 1:2,000 dilution), rabbit anti-p53 (ab131442, 1:500 dilution), rabbit anti-EGFR (ab131498, 1:500 dilution), rabbit anti-Bax (ab182733, 1:1,000 dilution), rabbit anti-Bcl-2 (ab32124, 1:1,000 dilution), rabbit anti-caspase-8 (ab25901, 1:1,000 dilution) and rabbit anti-GAPDH (ab37168, 1:1,000 dilution) antibodies were obtained from Abcam (Cambridge, MA, USA). Rabbit anti- $\alpha$-tubulin (2144, 1:1,000 dilution), rabbit anti-AKT (4691, 1:1,000 dilution), rabbit anti-phospho-AKT (4060, 1:1,000 dilution), rabbit anti-MEK1 (9146, 1:1,000 dilution), rabbit anti-phospho-MEK1 (98195, 1:1,000 dilution), rabbit anti-ERK1/2 (4695, 1:1,000 dilution), rabbit anti-phospho-ERK1/2 (4370, 1:1,000 dilution), rabbit anti-c-Raf (9422, 1:1,000 dilution) and rabbit anti-phospho-c-Raf (9421, 1:1,000 dilution) antibodies were purchased from Cell Signaling Technology (Danvers, MA, USA). Goat anti-rabbit IgG (H+L), HRP antibody (31460, 1:10,000 dilution) was obtained from Thermo Fisher Scientific.

Immunofluorescence assay. RBM10 antibody (1:200), anti-p53 antibody (1:200), or anti-EGFR antibody (1:200) (these antibodies were the same as the ones mentioned above) were added to the cells, followed by incubation with FITC-goat anti-rabbit antibody (1:200; ZF-0311, Zhongshan Biotechnology, Zhongshan, China) for $40 \mathrm{~min}$ at $23^{\circ} \mathrm{C}$ (away from light). After washing the cells in 0.1 M PBS, the expression levels of 

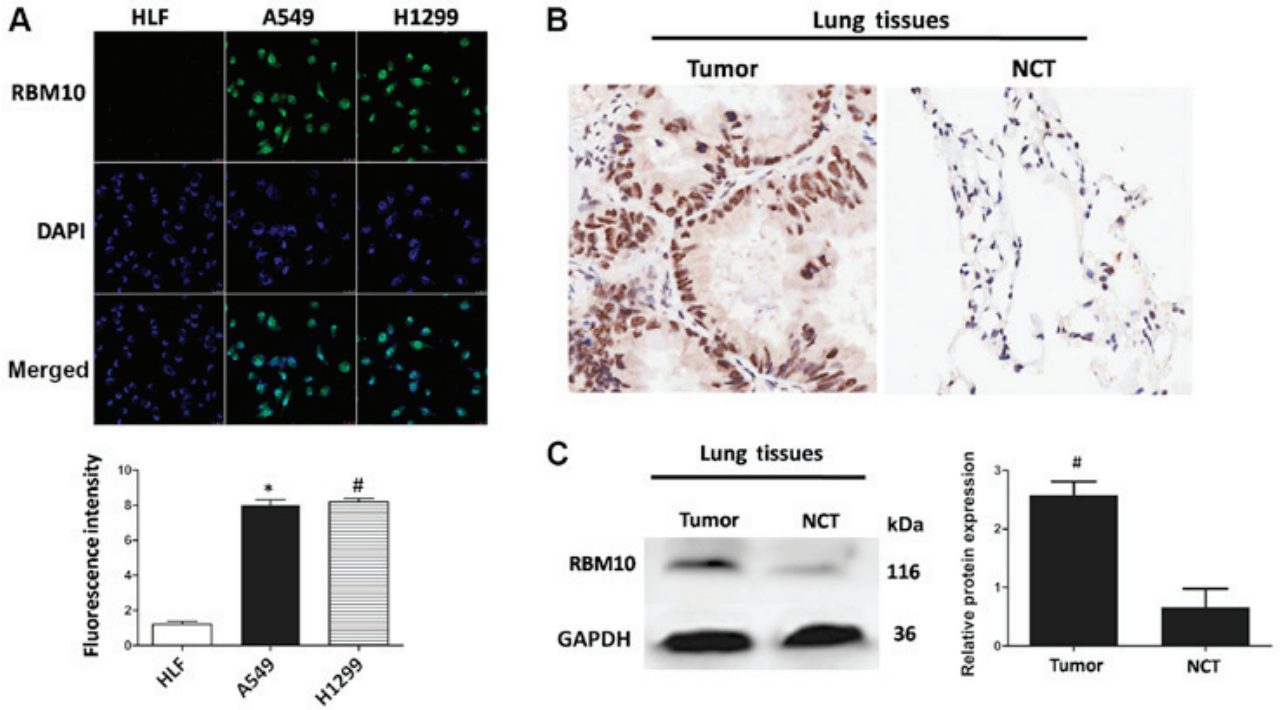

Figure 1. Protein expression of RBM10 in cells and tissues. (A) Protein expression of RBM10 examined by immunofluorescence assay; magnification, $\mathrm{x} 400$ and quantitative analysis of immunofluorescence assay ("P $<0.01$, A549 cells vs. the HLF cells and ${ }^{\#} \mathrm{P}<0.01$, H1299 cells vs. the HLF cells. (B) Expression of RBM10 examined immunohistochemistry in tumor tissues and NCTs ( $\mathrm{n}=6)$; magnification, $\mathrm{x} 400$. (C) Expression of RBM10 in tumor tissues and NCTs examined by western blot analysis and quantitative analysis; ${ }^{~} \mathrm{P}<0.05$ vs. NCT. NCT, (adjacent) non-cancerous tissues; HLF cells, human lung fibroblast cells.

RBM10, EGFR and p53 were observed under a fluorescence confocal microscope (Olympus BX63; Olympus, Tokyo, Japan).

Immunohistochemistry. The samples from the tissue microarray (the thickness of each section was $3 \mu \mathrm{m}$ ) were deparaffinized, endogenous peroxidase activity was quenched in $3 \% \mathrm{H}_{2} \mathrm{O}_{2}$ for $10 \mathrm{~min}$, and the sections were washed in PBS. They were then incubated with RBM10 antibody (1:300 dilution) for $1 \mathrm{~h}$, followed by incubation with the appropriate biotinylated secondary antibodies (Vector Laboratories, Burlingame, CA, USA) and treatment with avidin-biotin-coupling (ABC) reagent (Vector Laboratories), as recommended by the manufacturer. Color development was achieved with the substrate diaminobenzidine. Two independent pathologists reviewed and scored the degree of immunohistochemical staining according to the criteria below using a light microscope (Carl Zeiss, Thornwood, NY, USA).

Scoring method of immunohistochemical staining. For the 90 lung adenocarcinoma tissue samples, the protein expression level of RBM10 was evaluated as follows: for RBM10 staining in the nucleus and cytoplasm, the staining intensity was scored as $0 / 1+/ 2+/ 3+(0$, no; $1+$, light yellow; $2+$, yellow; $3+$, brown-yellow) and the staining positive rate scores (0, negative; $1,1-25 \% ; 2,26-50 \% ; 3,51-75 \%$ and $4,76-100 \%)$ were calculated (i.e., cancer tissues compared to the NCTs). ImageJ software (National Institutes of Health, Bethesda, MD, USA) was used here. The 'staining intensity scores' were multiplied by the 'staining positive rate scores' to yield a total score, by which patients were then grouped; that is, a sample with a score of $\leq 1$ was placed in the low expression group and a score of $>1$ was placed in the high expression group.

Cell wound scratch assay. Lines were drawn on the back of a 6-well plate with a marker pen, and the transverse lines were drawn uniformly at distances of $1 \mathrm{~cm}$ between the lines and 3 lines in each well. A total of $2 \times 10^{5}$ cells (H1299) were seeded into the plate and cultured at $37^{\circ} \mathrm{C}$ in an atmosphere of $5 \% \mathrm{CO}_{2}$. When the cells grew to $80 \%$ confluence, the medium was discarded and the cells were washed with PBS 3 times. Subsequently, a scratch was placed in the middle of the well with a sterile $200 \mu l$ pipette tip, and the cells were then washed with PBS 3 times. The cells were then cultured in RPMI-1640 medium containing $2 \% \mathrm{FBS}$ and $100 \mathrm{IU} / \mathrm{ml}$ penicillin/gentamycin at $37^{\circ} \mathrm{C}$. Images were captured using a DSC-HX1 digital camera (Sony Corp., Tokyo, Japan). Experiments were carried out in triplicate and repeated 3 times.

Cell colony formation assay. A total of 800 cells (A549 and H1299) were seeded into each well of 6-well plates and grown overnight, and were then transfected with the shRNAs. The cells were allowed to form colonies at the 4 day and then fixed with $4 \%$ paraformaldehyde for $15 \mathrm{~min}$, stained with crystal violet for $15 \mathrm{~min}$ at room temperature, and then washed 3 times with $\mathrm{dH}_{2} \mathrm{O}$. The cells were photographed with a digital camera (Leica, Wetzlar, Germany), and experiments were performed in triplicate and repeated 3 times.

Statistical analysis. Data are expressed as the means \pm standard deviation (SD) values. A Student's t-test was applied to compare 2 groups of independent data. One-way ANOVA with Tukey's post hoc test was used for multiple comparisons. The Chi-square test was used to evaluate the differences in the categorical variables. Survival curves were carried out using the Kaplan-Meier method and were compared between groups using the log-rank test. Statistical significance was set at $\mathrm{P}<0.05$. All statistical analyses were performed using the SPSS 17.0 software package (SPSS Inc., Chicago, IL, USA).

\section{Results}

RBM10 is overexpressed in lung adenocarcinoma cell lines and tissue samples. First we examined whether RBM10 protein was expressed in lung adenocarcinoma cell lines (A549 and H1299) 
A

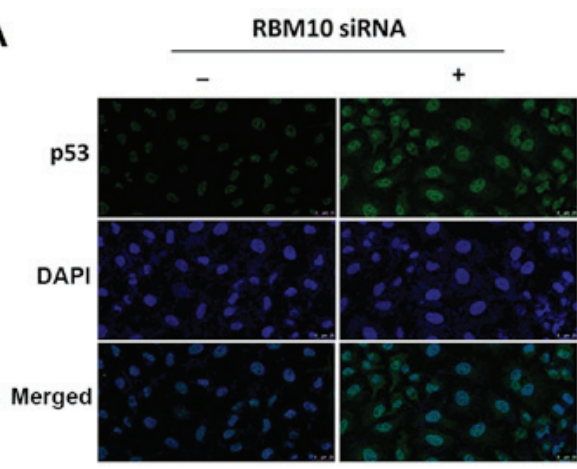

B

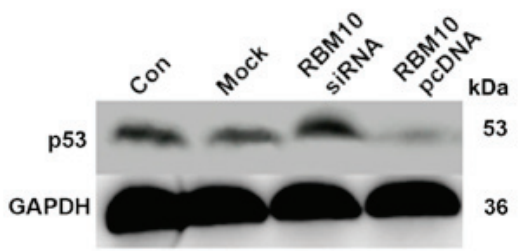

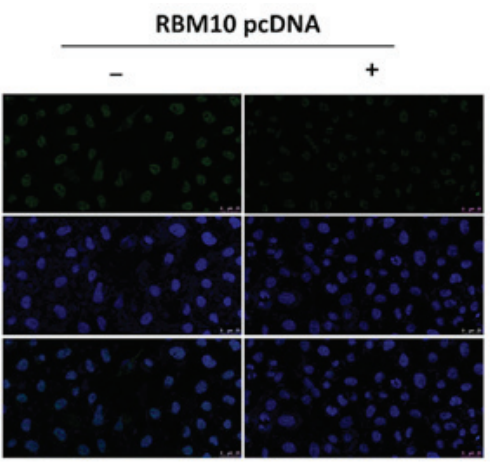

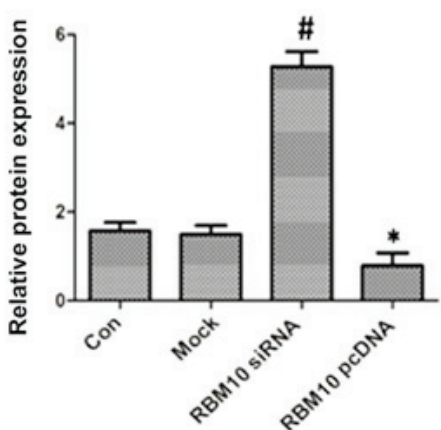

C
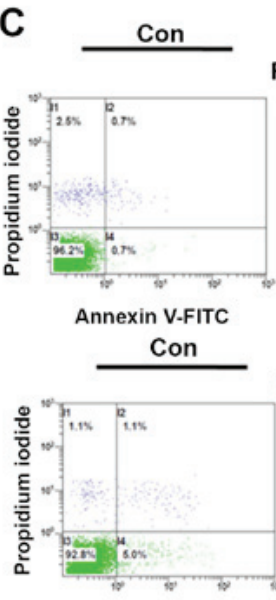

Annexin V-FITC

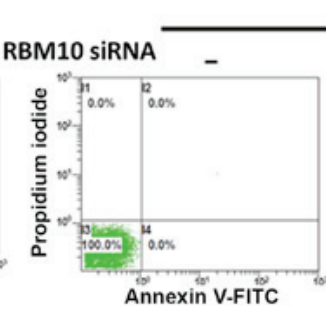

A549

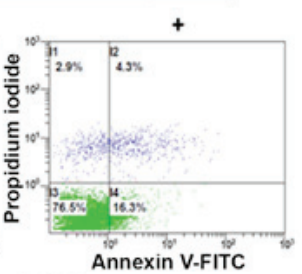

H1299
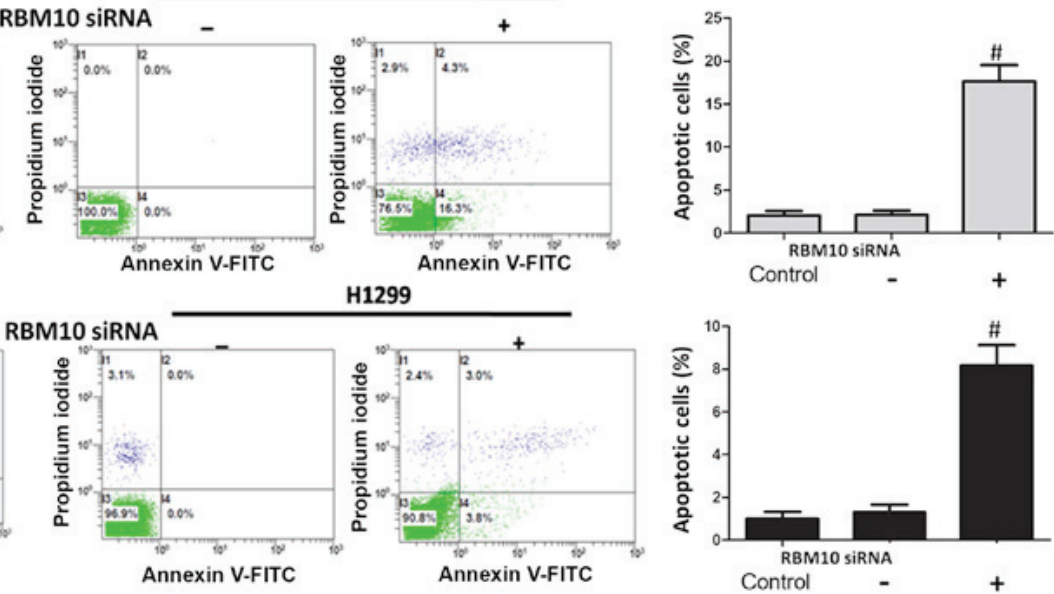

Figure 2. Effects of RBM10 protein on the apoptosis of tumor cells. (A) Effects of the downregulation or upregulation of RBM10 protein on p53 protein expression examined by immunofluorescence assay in A549 cells; magnification, x400. (B) Effects of the downregulation or upregulation of RBM10 on p53 expression in A549 cells examined by western blot analysis and quantitative analysis of the western blots. ${ }^{\#} \mathrm{P}<0.05$, RBM10 pcDNA3.1 group compared with the control or mock group and ${ }^{*} \mathrm{P}<0.05$, RBM10 siRNA group compared with the control or mock group. (C) The level of cell apoptosis following the knockdown of RBM10 protein, examined by flow cytometry and the apoptotic rate in A549 cells and H1299 cells. , ${ }^{\text {P }}<0.05$ vs. control or RBM10 siRNA (-) group.

using the green fluorescent protein RBM10. As shown in Fig. 1A, RBM10 was overexpressed in the lung adenocarcinoma cells near the cell nucleus compared to the HLFs $(\mathrm{P}<0.01)$; this result indicated that RBM10 may be overexpressed in the cell nucleus of lung adenocarcinoma cells.

To verify the expression of RBM10 in vitro, we further examined 6 pairs of lung adenocarcinoma tissues and the corresponding NCTs. Immunohistochemical staining of RBM10 protein revealed that the protein expression level of RBM10 in the lung adenocarcinoma tissues was significantly higher than that in the NCTs, and was mainly located in the nucleus (Fig. 1B). These results revealed that the protein expression of RBM10 in human lung adenocarcinoma tissues was markedly upregulated compared with that in the NCTs.

We also used western blot analysis to detect the protein expression of RBM10 in the 6 pairs of lung adenocarcinoma tissues and NCTs. The results revealed that the protein expression of RBM10 in the tumor tissues was significantly higher than that in NCTs (Fig. 1C), and the results of quantitative analysis revealed statistically significant differences between the 2 groups $(\mathrm{P}<0.05)$. It was further verified by quantitative analysis that the protein expression level of RBM10 in the lung adenocarcinoma tissues was higher than that in the normal tissues adjacent to the carcinoma.

Upregulation of RBM10 expression inhibits the apoptosis of lung adenocarcinoma cells. We then examined the effects of the upregulation (using a pcDNA3.1 plasmid) and downregulation (using an siRNA technique) of RBM10 expression on the apoptosis of A549 cells. At $48 \mathrm{~h}$ following transfection, the cells were stained using immunofluorescence. First, we examined the effect of RBM10 on the key tumor 
A

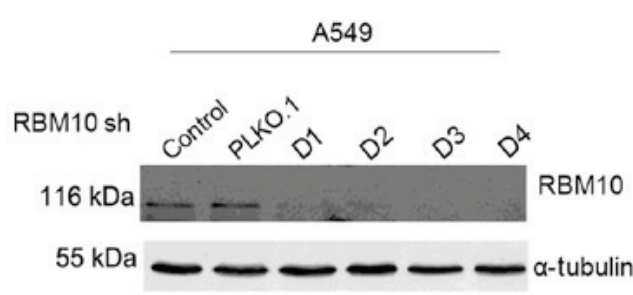

B

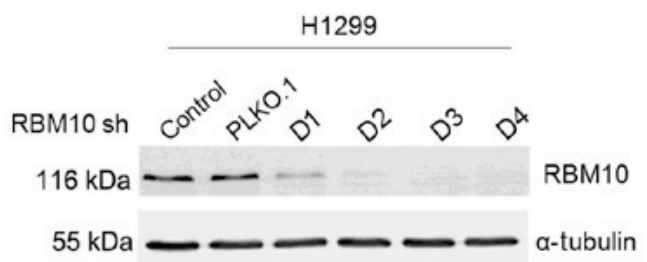

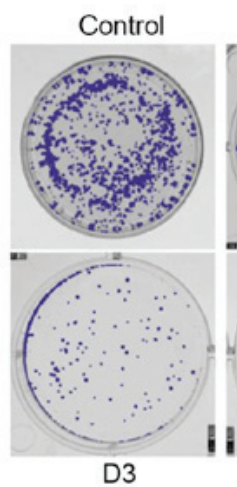

PLKO.1

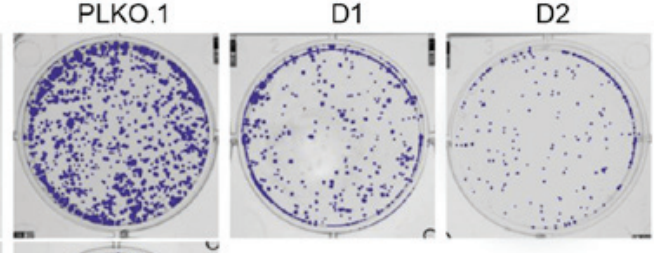

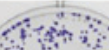

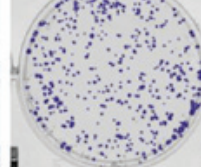

D4

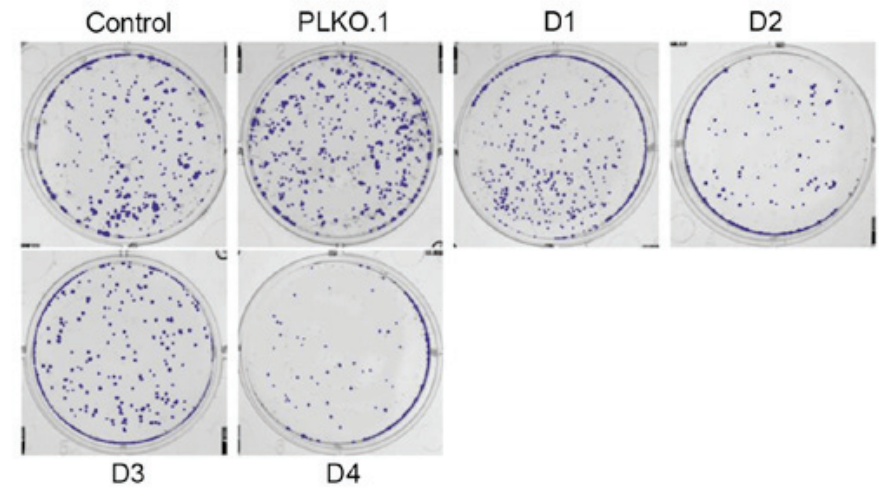

Figure 3. Evaluation of the proliferative ability of lung adenocarcinoma cells following the knockdown of RBM10 expression examined by cell colony formation assay. (A) In A549 cells, western blot analysis was used to verify the successful transfection of different DNA sequence cells and the cell proliferation on soft agar. (B) In H1299 cells, western blot analysis was used to verify the successful transfection of different DNA sequence cells and the cell proliferation on soft agar.

suppressor protein, p53; when RBM10 expression was upregulated in the A549 cells, the protein expression of $\mathrm{p} 53$ was decreased. However, when RBM10 protein expression was silenced, p53 protein expression was increased (Fig. 2A). The same results were obtained by western blot analysis, and exhibited statistical significance $(\mathrm{P}<0.05$; Fig. $2 \mathrm{~B})$.

Subsequently, we examined the effect of RBM10 on cell apoptosis by flow cytometry. At $48 \mathrm{~h}$ following transfection with RBM10 siRNA, the apoptotic rate of the A549 and H1299 cells markedly increased [ $\mathrm{P}<0.05$ vs. control or RBM10 siRNA (-) groups] (Fig. 2C). This result indicated that the upregulation of RBM10 protein may inhibit the apoptosis of the lung cancer cells.

Downregulation of RBM10 expression inhibits the proliferation of lung adenocarcinoma cells. We then investigated the association between RBM10 expression and the proliferation of lung adenocarcinoma cells. We transfected the A549 and H1299 cells with either RBM10 shRNA (with varying DNA sequences) or with a PLKO.1 carrier for $48 \mathrm{~h}$ and verified the transfection by western blot analysis. We found that the untransfected A549 and H1299 cells (control group), along with the PLKO.1 carrier-infected A549 and H1299 cells, grew to a medium extent in soft agar. Conversely, after the silencing of RBM10 expression with different DNA sequences (D1, D2, D3 and D4), the growth of the clones in soft agar culture medium and their ability to form cell colonies had weakened compared with that of the control group or the PLKO.1 carrier group (Fig. 3).
Downregulation of RBM10 expression inhibits the migration of lung adenocarcinoma cells. Tumor cell migration is important in the metastasis of lung adenocarcinomas. Therefore, we examined the effects of RBM10 on cell migration using a cell wound scratch assay. We found that at $24 \mathrm{~h}$ following transfection of the H1299 cells with RBM10 shRNA, the migration of the tumor cells was weaker compared with that of the control group and PLKO.1 vector control group (Fig. 4). This indicates that the downregulation of RBM10 protein expression in the lung adenocarcinoma cells inhibits cellular migration, whereas a high expression of RBM10 protein can promote tumor cell migration.

Upregulation of RBM10 expression increases EGFR expression in lung adenocarcinoma cells. EGFR is the key protein in the tumor proliferative signaling pathways. In this study, we examined the effect of RBM10 on the expression of EGFR by immunofluorescence staining. We found that the upregulation of RBM10 expression (via pcDNA3.1) increased EGFR expression in the cytosolic membrane of the A549 and H1299 cells, while the downregulation of RBM10 expression (via siRNA) decreased EGFR expression (Fig. 5A and B).

To further verify the results of immunofluorescence staining, we performed western blot analysis. We found that transfection with RBM10 siRNA downregulated the expression of EGFR in the lung adenocarcinoma cells compared with the control or mock groups $(\mathrm{P}<0.05)$ and transfection with RBM10 pcDNA3.1 upregulated the expression of EGFR $(\mathrm{P}<0.05$; Fig. 5C and D). 


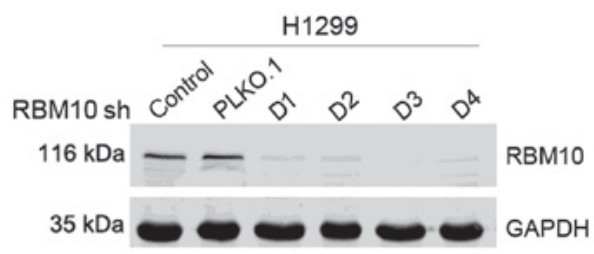

Control
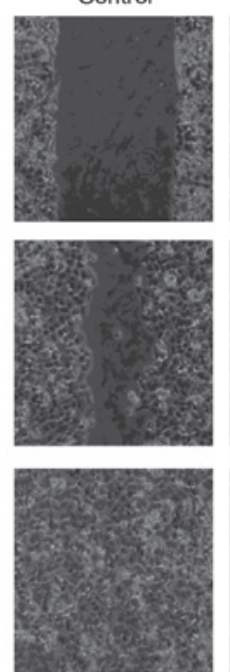

PLKO.1
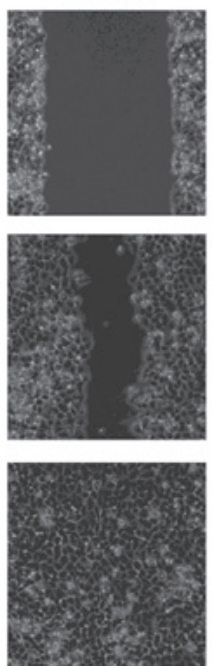

D1
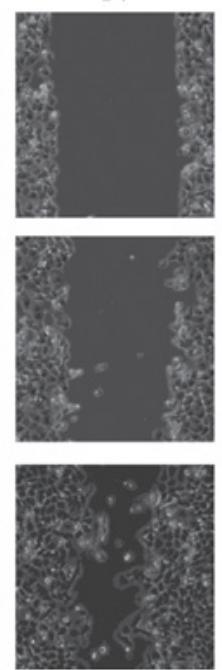

D2
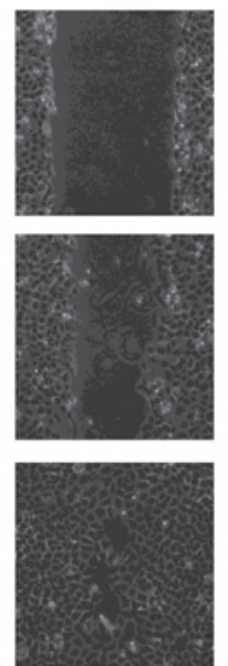

D3
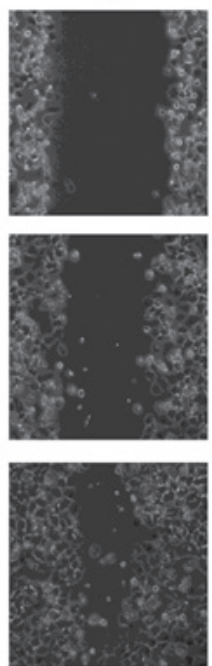

D4

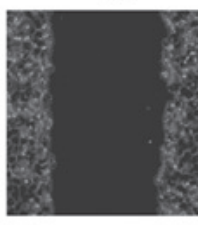

Oh

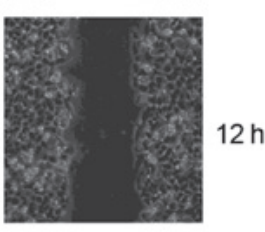

$24 \mathrm{~h}$

Figure 4. Effect of the knockdown of RBM10 expression on H1299 cell migration examined by cell wound scratch assay. Verification of decreased RBM10 levels after silencing by shRNA in H1299 cells by western blot analysis and cell migration compared with the control and vector control (PLKO.1) examined by cell wound scratch assays at 0,12 and $24 \mathrm{~h}$.

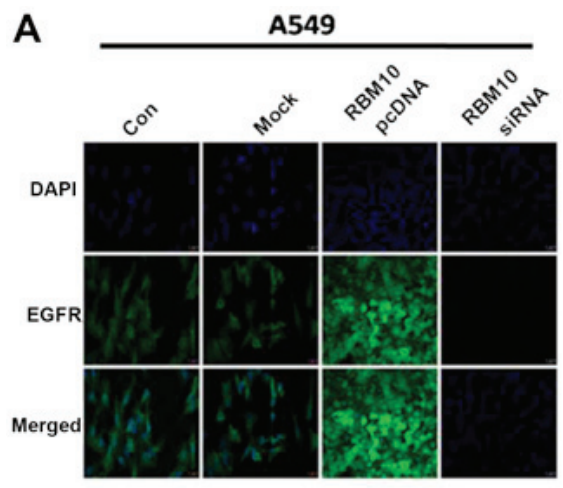

C
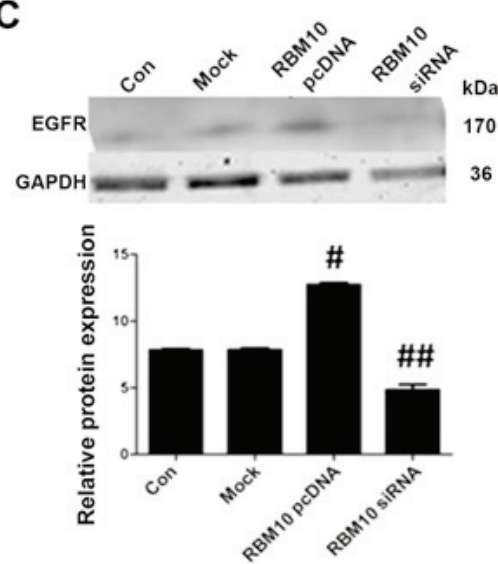

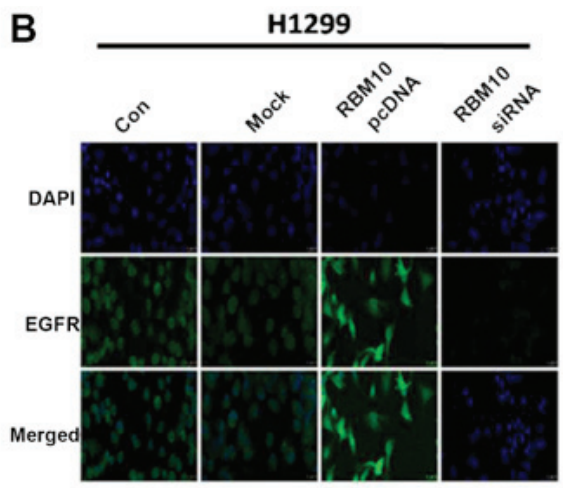

D
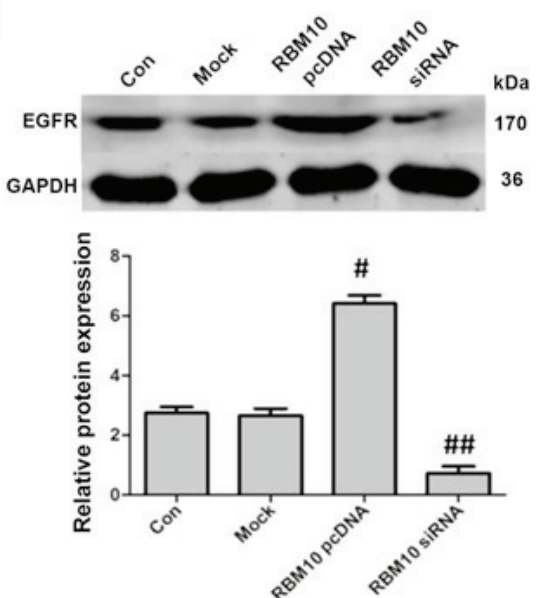

Figure 5. Effects of the upregulation or downregulation of RBM10 expression on EGFR expression. (A) Effects of RBM10 expression on EGFR expression in A549 cells examined by immunofluorescence assay; magnification, x400. (B) Effects of RBM10 expression on EGFR expression in H1299 cells examined by immunofluorescence assay; magnification, x400. (C) Effects of RBM10 expression on EGFR expression in A549 cells examined by western blot analysis and quantitative analysis of the western blots. (D) Effect of RBM10 expression on EGFR expression in H1299 cells examined by western blot analysis and quantitative analysis of the western blots. ${ }^{\#} \mathrm{P}<0.05$, RBM10 pcDNA3.1 group vs. control or mock group and ${ }^{\# \#} \mathrm{P}<0.05, \mathrm{RBM} 10$ siRNA group vs. control or mock group. 

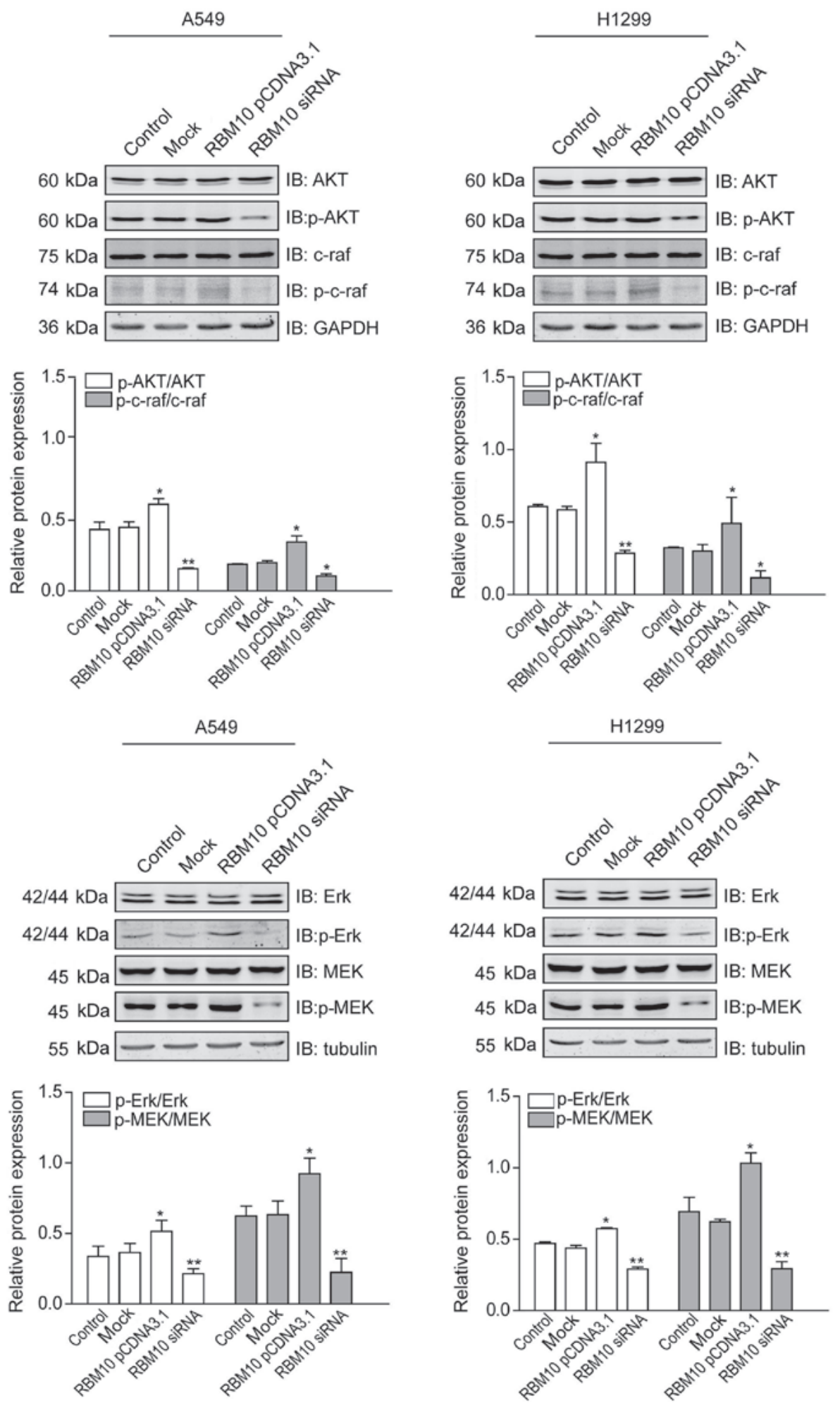

Figure 6. Effects of RBM10 protein levels on proliferative signaling pathways. Expression levels of key proteins in MAPK and PI3K signaling pathways following the upregulation or downregulation of RBM10 protein expression examined by western blot analysis and quantitative analysis of relative protein expression in A549 cells and $\mathrm{H} 1299$ cells. ${ }^{*} \mathrm{P}<0.05$ and ${ }^{* *} \mathrm{P}<0.01$, compared with control or mock groups.

Upregulation of RBM10 expression stimulates proliferative signaling pathways in lung adenocarcinoma cells. The EGFR-mediated activation of key signaling pathways is important for the proliferation of lung adenocarcinomas. Therefore, we then examined the effects of RBM10 expression on proteins within key proliferative signaling pathways (MAPK and PI3K) by western blot analysis. We found that
p-Akt, p-c-Raf, p-Erk, and p-MEK1 proteins were expressed at similar levels in the A549 and H1299 cells in the control or mock groups. RBM10 overexpression upregulated the expression levels of these proteins $(\mathrm{P}<0.05)$, while the downregulation of RBM10 expression by RBM10 siRNA downregulated the expression levels of these proteins, particularly those of p-Akt, p-Erk and p-MEK1 $(\mathrm{P}<0.01)$. No significant differences were 
A

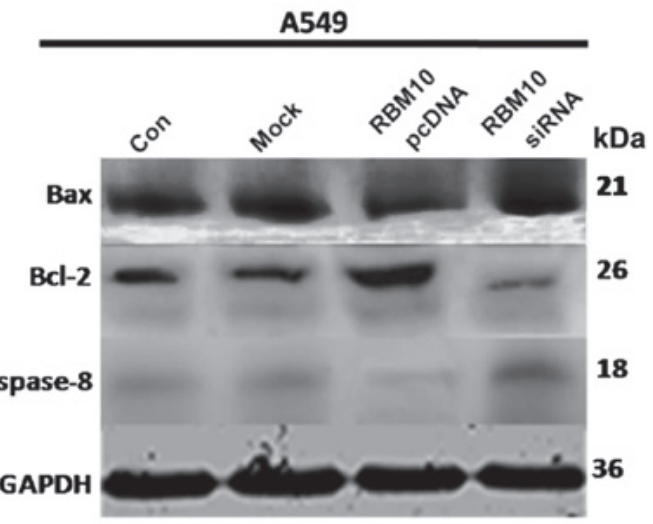

B

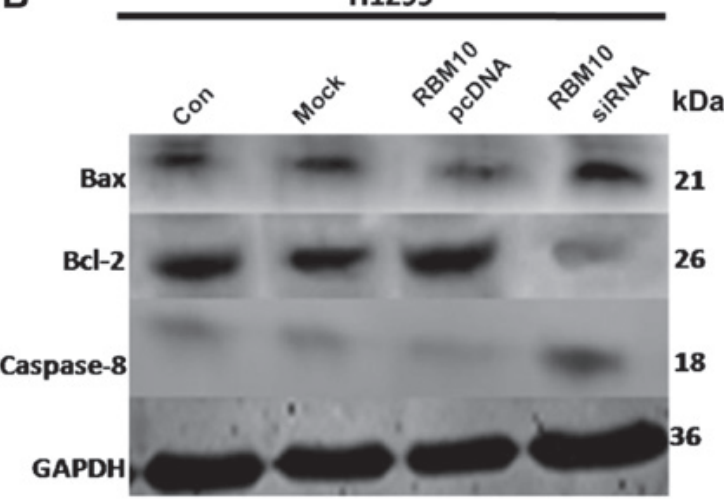

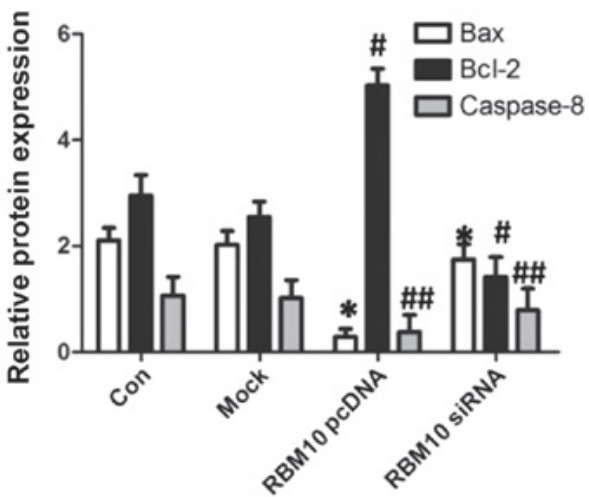

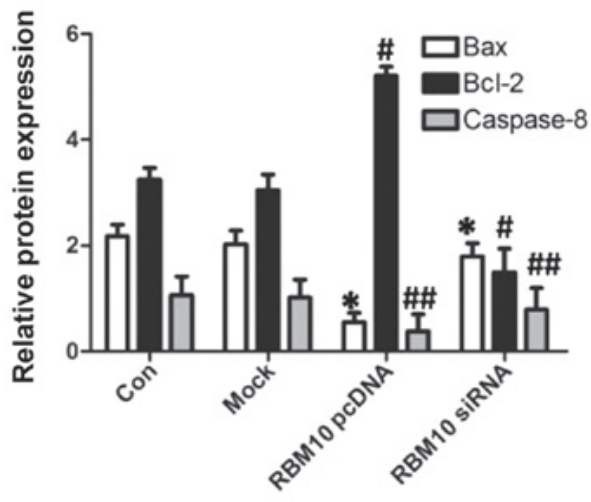

Figure 7. Effects of the upregulation or downregulation of RBM10 expression on apoptotic proteins (Bax, Bcl-2 and caspase-8). (A) Effects of RBM10 on apoptotic proteins examined by western blot analysis and quantitative analysis of relative protein expression in A549 cells. (B) Effect of RBM10 on apoptotic proteins examined by western blot analysis and quantitative analysis of relative protein expression in $\mathrm{H} 1299$ cells. $\mathrm{P}<0.05$, compared with the control or mock group ("Bax protein, ${ }^{\#}$ Bcl-2 protein, ${ }^{\# \#}$ caspase-8 protein).

observed in the total levels of Akt, c-Raf, Erk and MEK1 between the different groups in the two cell lines (Fig. 6). These findings indicate that the protein expression of RBM10 in lung adenocarcinoma cells can activate key proliferative signaling pathways.

Upregulation of RBM10 expression inhibits the stimulation of the apoptotic signaling pathways in lung adenocarcinoma cells. Studies have shown that the inhibition of classical apoptotic signaling pathways plays an important role in the pathogenesis of lung adenocarcinoma (16-18). In this study, we used western blot analysis to detect the expression levels of key proteins of apoptotic signaling pathways (including Bax, Bcl-2 and caspase-8) following the upregulation or downregulation of RBM10 expression. The overexpression of RBM10 decreased the expression levels of the pro-apoptotic proteins, Bax and caspase- 8 , whereas it increased the expression of the anti-apoptotic protein, Bcl-2 $(\mathrm{P}<0.05)$. However, RBM10 silencing increased the protein expression of Bax and caspase-8, and decreased the protein expression of Bcl-2 $(\mathrm{P}<0.05$; Fig. 7). These results indicate that a high expression of RBM10 protein may reduce the stimulation of the apoptotic signaling pathways in lung adenocarcinoma cells.

Associations of the levels of RBM10 protein expression with the clinicopathological characteristics of patients with lung adenocarcinomas. In order to better evaluate the associations of RBM10 protein expression levels and clinicopathological parameters in lung adenocarcinomas, we analyzed the case numbers of high expression and low expression of RBM10 protein in the nucleus and cytoplasm of lung adenocarcinomas, and the association analysis was performed on the TNM stage according to the 7 th edition of lung cancer (19) (Table I). The results revealed that the level of RBM10 protein expression was not related to sex and age, respectively ( $P>0.05, \chi^{2}$ test), but was associated with $\mathrm{T}$ stage and $\mathrm{N}$ stage $(\mathrm{P}=0.012$ and 0.046 , respectively; $\mathrm{P}<0.05, \chi^{2}$ test).

Association between RBM10 expression in lung adenocarcinomas and clinical prognosis. Immunohistochemical experiments were carried out in the tissue chip containing 90 cases of lung adenocarcinoma tissues and NCTs. We found that in the lung adenocarcinoma tissues, both in the nucleus and in the cytoplasm, the protein expression levels of RBM10 were higher than those in NCTs $(\mathrm{P}<0.05$; Table II); the high expression levels of RBM10 protein were more than those in NCTs.

We also obtained follow-up data of the 90 patients 5 years post-operatively and analyzed the survival rates in the RBM10-high and RBM10-low expression groups. We found that the protein expression of RBM10 in the tumor tissues, both in the nucleus and cytoplasm, was significantly associated with the patient survival time. Patients with a high expression level of RBM10 had a shorter overall survival time and a poor 
Table I. Associations of the protein expression levels of RBM10 with the clinicopathological characteristics of patients with lung adenocarcinoma.

\begin{tabular}{|c|c|c|c|c|}
\hline & $\begin{array}{c}\text { Total } \\
(n=69)\end{array}$ & $\begin{array}{c}\text { RBM10 } \\
\text { high expression } \\
(n=55)\end{array}$ & $\begin{array}{c}\text { RBM10 } \\
\text { low expression } \\
(n=14)\end{array}$ & P-value \\
\hline \multicolumn{5}{|l|}{ Sex } \\
\hline Male & 39 & 29 & 10 & 0.566 \\
\hline Female & 30 & 26 & 4 & \\
\hline \multicolumn{5}{|l|}{ Age (years) } \\
\hline$\geq 60$ & 36 & 32 & 4 & 0.434 \\
\hline$<60$ & 33 & 23 & 10 & \\
\hline \multicolumn{5}{|l|}{$\mathrm{N}$ stage } \\
\hline No & 44 & 32 & 12 & 0.046 \\
\hline $\mathrm{N} 1+\mathrm{N} 2$ & 25 & 23 & 2 & \\
\hline \multicolumn{5}{|l|}{ T stage } \\
\hline $\mathrm{T} 1+\mathrm{T} 2$ & 50 & 42 & 8 & 0.012 \\
\hline $\mathrm{T} 3+\mathrm{T} 4$ & 19 & 13 & 6 & \\
\hline
\end{tabular}

A value of $\mathrm{P}<0.05$ was considered to indicate a statistically significant difference.

Table II. Expression levels of RBM10 in tumors and NCTs.

\begin{tabular}{llr}
\hline & \multicolumn{2}{c}{ Patient no. (90) } \\
\cline { 2 - 3 } & Tumors & NCTs \\
\hline Nucleus & & 28 \\
RBM10 (high) & 60 & 62 \\
RBM10 (low) & 30 & \\
P-value & 0.037 & \\
Cytoplasm & & 88 \\
RBM10 (high) & 72 & \\
RBM10 (low) & 18 & \\
P-value & 0.042 & \\
\hline
\end{tabular}

A value of $\mathrm{P}<0.05$ was considered to indicate a statistically significant difference. NCTs, (adjacent) non-cancerous tissues.

prognosis compared to those with a low expression level of RBM10 (P<0.05; Fig. 8).

\section{Discussion}

Recent studies have indicated that $R B M 10$ gene is mutated in certain types of tumor, including pancreatic cancer, breast cancer, colon cancer and melanoma (10-12,20). It is also mutated in up to $21 \%$ of invasive lung adenocarcinomas (9) and $7 \%$ of lung adenocarcinomas (21). In a study on pancreatic cancer (10) remarkably, RBM10 gene mutations were associated with an enhanced survival, although all RBM10-mutated cases were of high grade. Of note, as they observed (10) in
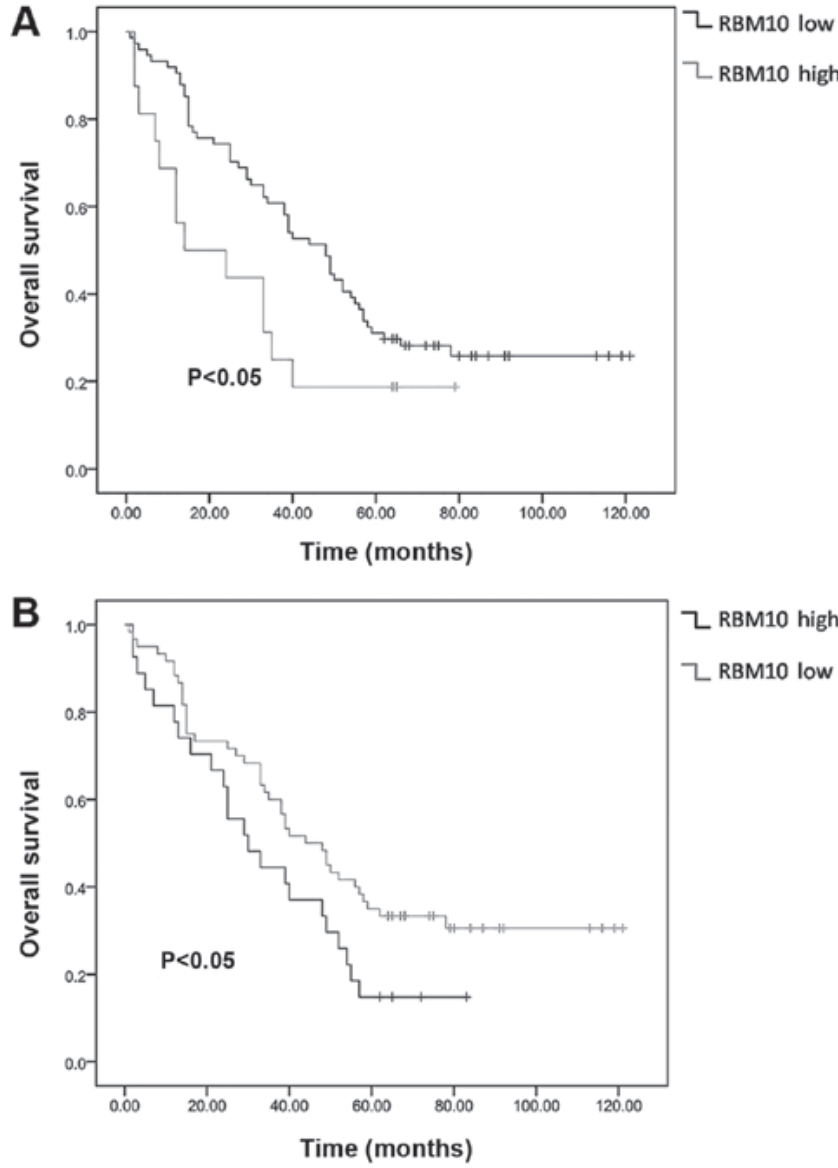

Figure 8. Associations of the different protein expression levels of RBM10 with the clinical prognosis of patients with lung adenocarcinoma. (A) Kaplan-Meier analysis of overall survival of patients with lung adenocarcinoma with different levels of RBM10 expression in the nucleus $(\mathrm{P}<0.05$, log-rank test). (B) Kaplan-Meier analysis of overall survival of lung adenocarcinoma patients with different levels of RBM10 expression in the cytoplasm $(\mathrm{P}<0.05, \log$-rank test).

the RBM10-mutated tumors, cases harbouring mutations at codon 61 paradoxically exhibited histological and clinical features indicative of poor survival. It can be speculated from the above that the effect of RBM10 mutations on the opposite prognosis may be related to the differential expression of mutations, some of which are highly expressed and some are low expression in tumors.

As RBM10 can influence cellular proliferation and apoptosis $(11,14,22)$, some studies have suggested that it functions as a tumor suppressor gene (11,22-24), while others consider it to be an oncogene $(15,25)$. To clarify the role of RBM10 in lung adenocarcinomas, we carried out related research.

In this study, we confirmed the association between RBM10 and lung adenocarcinomas both in vitro and in vivo. RBM10 was upregulated in lung adenocarcinoma cells and lung adenocarcinoma tissues, compared with normal lung cells and normal lung tissues adjacent to the tumor. Our findings are consistent with other findings $(21,22,25,26)$. We also demonstrated that RBM10 was mainly expressed in the cell nucleus, and to the best of our knowledge, this is the first time this has been reported.

We then examined the role of RBM10 in lung adenocarcinomas. By immunofluorescence assay and western 
blot analysis, we found that the overexpression of RBM10 reduced the expression of p53, which mainly affects the cell cycle and inhibits tumor cell invasion and proliferation by promoting apoptosis (27). Our flow cytometry experiments further verified that the downregulation of RBM10 expression led to the increased apoptosis of lung adenocarcinoma cells. Therefore, we hypothesized that RBM10 promotes the proliferation of lung adenocarcinomas by inhibiting apoptosis and may be a oncogene, which was also confirmed by other studies $(15,22)$.

The clone formation assay and cell wound scratch assay are experimental methods used to visually evaluate cell biological abilities. Our findings indicated that the abilities of cell proliferation and growth, as well as invasiveness and metastasis, were reduced following the downregulation of RBM10, which further indicates that, a high expression of RBM10 can promote the proliferation and metastasis of lung adenocarcinoma cells. Thus, we hypothesized that RBM10 is an oncogene in lung adenocarcinomas. Some researchers have also come to this conclusion $(15,20)$.

EGFR protein is at the head of one of the most important signaling pathways in mammalian cell physiology and oncogenesis (6). First, we demonstrated that RBM10 expression is positively associated with EGFR expression. We then detected several key proteins (p-AKT, p-c-RAF, p-ERK and p-MEK) in the MAPK and PI3K signaling pathways activated by EGFR, which play key roles in tumor proliferation (6). Likewise, we found that the level of RBM10 expression was positively related to these key proteins, which indicates that RBM10 plays a functional role in stimulating proliferation in lung adenocarcinoma. This finding is in line with some previous findings (25), although others have found opposite results (28).

In this study, there may be such a question: RBM10 is mainly expressed in the nucleus, and EGFR is mainly expressed on the cell membrane. The mechanism through which RBM10 affect EGFR should be considered. We consider the following: i) There may be some type of crosstalk between RBM10 and EGFR in the lung adenocarcinoma cells that express RBM10 and EGFR; ii) research has indicated that in specific cases, EGFR can be translocated to the nucleus to play a role, although the specific mechanisms are not clear $(29,30)$, and iii) in some cases, RBM10 can sometimes appear in the cytoplasm (31).

Subsequently, we detected the effects of RBM10 on tumor apoptosis. We found that the overexpression of RBM10 decreased the expression levels of pro-apoptotic proteins, such as Bax and caspase- 8 , whereas it increased that of the anti-apoptotic protein, Bcl-2. However, the silencing of RBM10 increased the protein expression levels of Bax and caspase- 8 , and decreased the protein expression of Bcl-2. This finding is supported by previous findings (25). Thus, it can be hypothesized that RBM10 plays a role in promoting apoptosis in lung adenocarcinoma. Some scholars have come to the opposite conclusion $(23,28,32)$; that is, the anti-apoptotic effect of RBM10. At the same time, there are also studies showing that RBM10 does not affect the selective splicing of caspase-9, caspase-3, caspase-2 and c-FLIP, which does not affect their expression levels (33).

Finally, when examining the clinical samples of 90 cases from a tissue microarray, we found that the expression level of
RBM10 in the nucleus and cytoplasm of lung cancer tissues was higher than that of normal tissue adjacent to the tumor. This is in line with our cytological experiments. In addition, the expression of RBM10 in NCTs was also consistent with the low expression of our cytological experiments in HLFs. As RBM10 can affect the metabolism of DNA molecules and a variety of cellular processes, it is necessary for the development $(34,35)$, growth and metabolism of normal cells $(14,36)$.

In this study, we also examined the associations between the expression of RBM10 and the clinicopathological indicators of lung adenocarcinoma, such as sex, age, $\mathrm{T}$ stage and $\mathrm{N}$ stage. RBM10 was highly expressed in males and in patients $>60$ years of age, although there was no statistical association. The high expression level in males was consistent with the results of gene sequencing of 230 cases of lung adenocarcinoma with the cancer genome research network, that is, the RBM10 mutation is greater among males (2). The association between RBM10 and age has not been reported, at least to the best of our knowledge. We demonstrated that the expression of RBM10 was higher in older aged patients, and it may also be associated with the increase in age and the increased incidence of lung adenocarcinoma. In addition, the deletion of RBM5 and RBM6 in other family members can be observed in smokers (37); however, to the best of our knowledge, there is no study available on RBM10 and smoking. Due to the incomplete information on smoking in this study, it is impossible to carry out the related analysis. In combination with the similarity between RBM10 and the structure of RBM5 and RBM6, the above-mentioned results can not exclude the effect of smoking in some patients. Of course, the experimental results that we obtained may also be related to our small sample size.

The high expression of RBM10 was associated with the $\mathrm{T}$ stage and $\mathrm{N}$ stage of lung adenocarcinoma, indicating that RBM10 can promote tumor growth, proliferation and lymph node metastasis, and increase the malignant biological behavior of the tumor, that is to play the role of an oncogene, which is consistent with the results of our cytological experiments. Similar studies have been conducted on breast cancer. Elevated levels of RBM6 and RBM10v2 RNA are associated with the progression of tumor grade, increased tumor size, progression of intraductal carcinoma in situ carcinoma and the loss of progesterone receptor expression. It is suggested that a coordinated expression of specific RBM6 and RBM10v2 variables is important for the occurrence of breast cancer (11). It is also suggested that the expression and function of RBM10 in tumors are not isolated, but also influenced by other RNA splicing proteins in the family.

The most important method for evaluating the clinical efficacy of an index is the survival curve. Therefore, in this study, through the analysis of the high and low expression of RBM10 in the tissue microarray of lung adenocarcinoma, we found that patients with high levels of RBM10 expression (in the nucleus and cytoplasm) had a shorter overall survival and a poorer prognosis. This is consistent with the clinicopathological findings, that is, the higher the T stage level is, the higher the lymph node metastasis is in patients with RBM10 high expression of lung adenocarcinoma. Therefore, it is suggested that the high expression of RBM10 is a poor 
prognostic indicator. To the best of our knowledge, we are the first to analyze the association between RBM10 expression and the survival of patients with lung adenocarcinoma. This result is in line with the findings of a previous study on breast cancer (11), and opposite to the findings of another study on pancreatic cancer (10).

At present, there are different opinions about whether RBM10 is a cancer-suppressor gene or an oncogene. In previous studies, opposing results have been found $(22,26,38)$; however, the current study can partly explain the contradictory findings. RBM10 has three variants (RBM10v1, RBM10v2 and RBM10v3), with RBM10v1 and RBM10v2 playing the leading roles $(11,23,39)$. In addition, RBM10v1 can promote proliferation, while RBM10v2 increases apoptosis (25). Thus, we hypothesized that the reason why RBM10 plays differential roles in the progression of lung adenocarcinoma may be associated with the composition ratio between the two RBM10 variants. As the composition ratio of RBM10v1 and RBM10v2 is diverse among different mutated lung adenocarcinomas, and even among other tumor types, the resulting effects of RBM10 will differ. In future experiments, we aim to investigate the composition ratio of these two variants in lung adenocarcinomas.

In conclusion, this study confirms that RBM10 plays an important role in the progression of lung adenocarcinomas by regulating both proliferative and apoptotic signaling pathways. We propose that RBM10 may be an oncogene, and may represent a novel therapeutic target for the treatment of lung adenocarcinomas.

\section{Acknowledgements}

Not applicable.

\section{Funding}

This study was supported by National Natural Science Foundation of China (NSFC) (grant no. 81774078).

\section{Availability of data and materials}

All data generated or analyzed during this study are included in this published article.

\section{Authors' contributions}

XS, MJ and WS performed the research. TW, CG and XS conceived and designed the study. XS, WS and LF analyzed the data, TW, CG and XS wrote the manuscript.

\section{Ethics approval and consent to participate}

For the use of patient samples, informed consent was obtained from all patients. This study was approved by the Human Research Ethics Committee of the First Affiliated Hospital of Dalian Medical University.

\section{Patient consent for publication}

Not applicable.

\section{Competing interests}

The authors declare that they have no competing interests.

\section{References}

1. Ferlay J, Soerjomataram I, Dikshit R, Eser S, Mathers C, Rebelo M, Parkin DM, Forman D and Bray F: Cancer incidence and mortality worldwide: Sources, methods and major patterns in GLOBOCAN 2012. Int J Cancer 136: E359-E386, 2015.

2. Collisson EA, Campbell JD, Brooks AN, Berger AH, Lee W, Chmielecki J, Beer DG, Cope L, Creighton CJ, Danilova L, et al; Cancer Genome Atlas Research Network: Comprehensive molecular profiling of lung adenocarcinoma. Nature 511: 543-550, 2014.

3. Ferlay J, Shin H-R, Bray F, Forman D, Mathers C and Parkin DM: Estimates of worldwide burden of cancer in 2008: GLOBOCAN 2008. Int J Cancer 127: 2893-2917, 2010.

4. Mehlen P and Puisieux A: Metastasis: A question of life or death. Nat Rev Cancer 6: 449-458, 2006.

5. Milkovic L, Siems W, Siems R and Zarkovic N: Oxidative stress and antioxidants in carcinogenesis and integrative therapy of cancer. Curr Pharm Des 20: 6529-6542, 2014.

6 . Wee P and Wang Z: Epidermal growth factor receptor cell proliferation signaling pathways. Cancers (Basel) 9: 3-45, 2017.

7. Milik SN, Lasheen DS, Serya RAT and Abouzid KAM: How to train your inhibitor: Design strategies to overcome resistance to Epidermal Growth Factor Receptor inhibitors. Eur J Med Chem 7: 1-21, 2017.

8. Zhao J, Sun Y, Huang Y, Song F, Huang Z, Bao Y, Zuo J, Saffen D, Shao Z, Liu W, et al: Functional analysis reveals that RBM10 mutations contribute to lung adenocarcinoma pathogenesis by deregulating splicing. Sci Rep 7: 40488, 2017.

9. Vinayanuwattikun C, Le Calvez-Kelm F, Abedi-Ardekani B, Zaridze D, Mukeria A, Voegele C, Vallée M, Purnomosari D, Forey N, Durand G, et al: Elucidating genomic characteristics of lung cancer progression from in situ to invasive adenocarcinoma. Sci Rep 6: 31628, 2016.

10. Witkiewicz AK, McMillan EA, Balaji U, Baek G, Lin WC, Mansour J, Mollaee M, Wagner KU, Koduru P, Yopp A, et al: Whole-exome sequencing of pancreatic cancer defines genetic diversity and therapeutic targets. Nat Commun 6: 6744,2015

11. Rintala-Maki ND, Goard CA, Langdon CE, Wall VE, Traulsen KE, Morin CD, Bonin $M$ and Sutherland LC: Expression of RBM5-related factors in primary breast tissue. J Cell Biochem 100: 1440-1458, 2007.

12. Giannakis M, Mu XJ, Shukla SA, Qian ZR, Cohen O, Nishihara R, Bahl S, Cao Y, Amin-Mansour A, Yamauchi M, et al: Genomic correlates of immune-cell infiltrates in colorectal carcinoma. Cell Reports 15: 857-865, 2016.

13. Jackson TC, Du L, Janesko-Feldman K, Vagni VA, Dezfulian C, Poloyac SM, Jackson EK, Clark RS and Kochanek PM: The nuclear splicing factor RNA binding motif 5 promotes caspase activation in human neuronal cells, and increases after traumatic brain injury in mice. J Cereb Blood Flow Metab 35: 655-666, 2015.

14. Loiselle JJ and Sutherland LC: Differential downregulation of Rbm5 and Rbm10 during skeletal and cardiac differentiation. In Vitro Cell Dev Biol Anim 50: 331-339, 2014.

15. Rodor J, FitzPatrick DR, Eyras E and Cáceres JF: The RNA-binding landscape of RBM10 and its role in alternative splicing regulation in models of mouse early development. RNA Biol 14: 45-57, 2017.

16. Hanahan D and Weinberg RA: The hallmarks of cancer. Cell 100: 57-70, 2000.

17. Fulda S: Evasion of apoptosis as a cellular stress response in cell. Int J Cell Biol 2: 1-6, 2010.

18. Plati J, Bucur O and Khosravi-Far R: Dysregulation of apoptotic signaling in cancer: Molecular mechanisms and therapeutic opportunities. J Cell Biochem 104: 1124-1149, 2008.

19. Goldstraw P, Crowley J, Chansky K, Giroux DJ, Groome PA, Rami-Porta R, Postmus PE, Rusch V and Sobin L; International Association for the Study of Lung Cancer International Staging Committee; Participating Institutions: The IASLC Lung Cancer Staging Project: Proposals for the revision of the TNM stage groupings in the forthcoming (seventh) edition of the TNM Classification of malignant tumours. J Thorac Oncol 2: 706-714, 2007. 
20. Garrisi VM, Strippoli S, De Summa S, Pinto R, Perrone A Guida G, Azzariti A, Guida M and Tommasi S: Proteomic profile and in silico analysis in metastatic melanoma with and without BRAF mutation. PLoS One 9: e112025, 2014

21. Imielinski M, Berger AH, Hammerman PS, Hernandez B, Pugh TJ, Hodis E, Cho J, Suh J, Capelletti M, Sivachenko A, et al: Mapping the hallmarks of lung adenocarcinoma with massively parallel sequencing. Cell 150: 1107-1120, 2012.

22. Bechara EG, Sebestyén E, Bernardis I, Eyras E and Valcárcel J: RBM5, 6, and 10 differentially regulate NUMB alternative splicing to control cancer cell proliferation. Mol Cell 52: 720-733, 2013.

23. Wang K, Bacon ML, Tessier JJ, Rintala-Maki ND, Tang V and Sutherland LC: RBM10 modulates apoptosis and influences TNF- $\alpha$ gene expression. J Cell Death 5: 1-19, 2012.

24. Hernández J, Bechara E, Schlesinger D, Delgado J, Serrano L and Valcárcel J: Tumor suppressor properties of the splicing regulatory factor RBM10. RNA Biol 13: 466-472, 2016.

25. Julie J: Loiselle1, Justin G. Roy, Leslie C. Sutherland: RBM10 promotes transformation-associated processes in small cell lung cancer and is directly regulated by RBM5. PLoS One 12: 1-23, 2017.

26. Tessier SJ, Loiselle JJ, McBain A, Pullen C, Koenderink BW, Roy JG and Sutherland LC: Insight into the role of alternative splicing within the RBM10v1 exon 10 tandem donor site. BMC Res Notes 8: 46, 2015.

27. Vogelstein B, Lane D and Levine AJ: Surfing the p53 network. Nature 408: 307-310, 2000

28. Martín-Garabato E, Martínez-Arribas F, Pollán M, Lucas AR, Sánchez J and Schneider J: The small variant of the apoptosis-associated X-chromosome RBM10 gene is co-expressed with caspase-3 in breast cancer. Cancer Genomics Proteomics 5: 169-173, 2008 .

29. Lo HW, Xia W, Wei Y, Ali-Seyed M, Huang SF and Hung MC: Novel prognostic value of nuclear epidermal growth factor receptor in breast cancer. Cancer Res 65: 338-348, 2005.

30. Psyrri A, Yu Z, Weinberger PM, Sasaki C, Haffty B, Camp R, Rimm D and Burtness BA: Quantitative determination of nuclear and cytoplasmic epidermal growth factor receptor expression in oropharyngeal squamous cell cancer by using automated quantitative analysis. Clin Cancer Res 11: 5856-5862, 2005.
31. Xiao SJ, Wang LY, Kimura M, Kojima $\mathrm{H}$, Kunimoto $\mathrm{H}$, Nishiumi F, Yamamoto N, Nishio K, Fujimoto S, Kato T, et al: S1-1/RBM10: Multiplicity and cooperativity of nuclear localisation domains. Biol Cell 105: 162-174, 2013.

32. Dvinge H, Kim E, Abdel-Wahab O and Bradley RK: RNA splicing factors as oncoproteins and tumour suppressors. Nat Rev Cancer 16: 413-430, 2016.

33. Inoue A, Yamamoto N, Kimura M, Nishio K, Yamane H and Nakajima K: RBM10 regulates alternative splicing. FEBS Lett 588: 942-947, 2014.

34. Lukong KE, Chang KW, Khandjian EW and Richard S: RNA-binding proteins in human genetic disease. Trends Genet 24: 416-425, 2008

35. Ozuemba B, Masilamani TJ, Loiselle JJ, Koenderink B, Vanderbeck KA, Knee J, Larivière $C$ and Sutherland LC: Co- and post-transcriptional regulation of Rbm5 and $\mathrm{Rbm} 10$ in mouse cells as evidenced by tissue-specific, developmental and disease-associated variation of splice variant and protein expression levels. Gene 580: 26-36, 2016.

36. Johnston JJ, Sapp JC, Curry C, Horton M, Leon E, Cusmano-Ozog K, Dobyns WB, Hudgins L, Zackai E and Biesecker LG: Expansion of the TARP syndrome phenotype associated with de novo mutations and mosaicism. Am J Med Genet A 164A: 120-128, 2014.

37. Angeloni D: Molecular analysis of deletions in human chromosome 3p21 and the role of resident cancer genes in disease. Brief Funct Genomics Proteomics 6: 19-39, 2007.

38. Martínez-Arribas F, Agudo D, Pollán M, Gómez-Esquer F, Díaz-Gil G, Lucas R and Schneider J: Positive correlation between the expression of X-chromosome RBM genes (RBMX, RBM3, RBM10) and the proapoptotic Bax gene in human breast cancer. J Cell Biochem 97: 1275-1282, 2006.

39. Sutherland LC, Rintala-Maki ND White RD and Morin CD RNA binding motif (RBM) proteins: A novel family of apoptosis modulators? J Cell Biochem 94: 5-24, 2005.

This work is licensed under a Creative Commons Attribution-NonCommercial-NoDerivatives 4.0 International (CC BY-NC-ND 4.0) License. 